\title{
Cervical Angina: A Literature Review on Its Diagnosis, Mechanism, and Management
}

\author{
Fan Feng, Xiuyuan Chen, Hongxing Shen \\ Department of Spine Surgery, Renji Hospital, Shanghai Jiaotong University School of Medicine, Shanghai, China
}

Cervical angina has been defined as chest pain that resembles true cardiac angina but originates from the disorders of the cervical spine. Thus, physicians and spine surgeons alike should raise awareness of this unusual condition for diagnosis and treatment. Particularly when neurologic signs and symptoms are present, there should be a strong suspicion for cervical angina in any patient with inadequately explained noncardiac chest pain. Cervical angina can be diagnosed according to negative cardiac workups, positive neurologic examination, and cervical radiographic findings (herniated disk, spinal cord compression, or foraminal encroachment). However, the mechanisms of pain production in cervical angina remain unclear. Previous studies attributed the pain to cervical nerve root compression, cervical sympathetic afferent fibers, referred pain, or lesions of the posterior horn of the spinal cord. Conservative treatments, which include neck collar fixation, head traction, and nonsteroidal anti-inflammatory drugs, have been determined to be successful in most patients with cervical angina. But when conservative treatment fails, anterior cervical surgery with complete decompression of the spinal cord and/or nerve root has been identified to effectively relieve cervical angina symptoms.

Keywords: Cervical angina; Cervical spondylosis; Chest pain; Surgery

\section{Introduction}

Chest pain is a common and highly challenging clinical problem in emergency departments. However, only $15 \%-$ $25 \%$ of patients with acute chest pain actually have acute coronary syndrome [1]. Most patients undergo cardiac "rule-out" and are diagnosed with noncardiac chest pain. Noncardiac chest pain is identified to occur in various gastrointestinal diseases (e.g., esophageal, gastric, biliarypancreatic), but it can be also caused by skeletal conditions. Cervical angina is a kind of anterior chest pain that resembles angina pectoris but originates from cervical spine disorders [2-4].
Although some previous investigators have provided details on this condition [3,5-7], cervical angina still appears to be neglected in the routine clinical practice. Iwasa [8] has reported that only $4.7 \%$ of patients with angina pectoris underwent cervical nerve root compression. Nakajima et al. [3] reviewed 706 patients who underwent cervical spine surgeries and found that $1.4 \%$ of them were considered to have cervical angina. However, because many patients with cervical angina cannot get prompt and accurate diagnosis, true incidence seems to be actually higher. In addition, many of them had been told that their disorder was psychogenic or untreatable. Patients with cervical angina usually experience anxiety, depres-

Received May 27, 2020; Revised Jul 30, 2020; Accepted Jul 30, 2020

Corresponding author: Hongxing Shen

Department of Spine Surgery, Renji Hospital, Shanghai Jiaotong University School of Medicine, No. 160 Pujian Road, Shanghai 200120, China

Tel: +86-021-68383204, Fax: +86-021-58394262, E-mail: hxshenrenji@163.com 
sion, and disabled activities of daily living. Therefore, it is necessary to review previous literatures regarding cervical angina and present our experience and findings to further raise awareness of this disorder.

\section{Definition}

In 1927, Phillips [5] first described symptomatic patients who exhibited cervical spondylosis and paroxysmal anginoid pain, without any cardiac function abnormalities. In 1934, Nachlas [6] reported three cases of pseudo-angina pectoris emerging from cervical spondylosis. He hypothesized that a "protopathic" pain was induced by ventral motor root compression. Other early classical literatures also reported cases of precordial pain that was attributed to cervical arthritis or herniated cervical disks [9-11]. In 1950, Davis [12] first proposed "cervical angina" as a clinical syndrome. In more recent publications, investigators used "cervical angina" as the diagnosis name $[2-4,7,13]$.

\section{Presentation and Diagnostics}

Patients with cervical angina often present with anterior chest pain that has been described as sharp, achy, or crushing in quality. The pain may be present at rest or exacerbated by cervical range of motion or movement of the upper extremity, usually persisting for $>30$ minutes or $<5$ seconds [14], and it can be either paroxysmal or continuous. Associated symptoms usually include neck pain, upper arm radicular symptoms (weakness or sensory changes), and occipital headaches. Furthermore, more than half of patients have been identified to experience autonomic symptoms such as dyspnea, nausea, vertigo, diplopia, and other sympathetic nervous signs $[3,4,7]$. According to the observation of Nakajima et al. [3], left chest pain tended to appear as a radicular sign, whereas retrosternal and epigastric pain and autonomic symptoms tended to be accompanied with myelopathy. Although cervical angina may present in various forms, certain features in the patient's physical examination should increase suspicion for cervicogenic chest pain. The patients usually have restricted cervical motion, paraspinal tenderness, and/or positive Spurling maneuver. Jacobs [2] revealed that common manifestations associated with cervical angina include neck and arm pain, upper arm radicular symptoms and fatigue, parasternal tenderness, and occipital headache. There are also some presumptive signs of noncardiac chest pain such as localization with one finger, radiation to the nuchal area, an inflammatory primary site, and pain that is relieved within a few seconds of swallowing food [3].

Cervical angina appears to be a relatively unknown clinical syndrome compared with other angina symptoms. The neurologic symptoms are often neglected in many cases. A prompt diagnosis of this underrecognized disorder requires an awareness of the common presenting features of cervical angina and a strong sense of suspicion in patients with inadequately explained chest pain. Varying degrees of cardiac workups must be performed in order to rule out true angina pectoris. Conventional criteria, such as response to nitrites, resting and stress electrocardiogram, or the character of pain, all carry a reasonably high percentage of error. Importantly, the use of coronary angiography has enabled us to rule out heart disease as the cause of chest wall pain more often and with greater accuracy than in the past $[4,7]$. Cervical imaging can be critical evidence in the diagnosis of cervical angina once coronary artery disease has been adequately ruled out [15]. Routine cervical magnetic resonance imaging (MRI) examination has been recommended for the functional assessment of cervical angina. MRI may demonstrate degenerative changes in the cervical spine, including herniated disk, spinal cord compression, or foraminal encroachment. Concordant medical history, examination, and radiographic findings support the diagnosis of cervical angina.

However, additional testing may be necessary in cases of a discrepancy between the clinical, radiographic, and neurophysiological findings. Degenerative changes are frequently found in the asymptomatic population, and functional tests may help to confirm the etiology of cervical angina. Diagnostic discography or selective nerve root block remains to be a useful tool to make functional diagnosis of cervical angina. However, these invasive tests, which are not risk-free, should be considered carefully and only applied in patients contemplating surgery [16].

Furthermore, when coronary angiography fails to explain the patient's angina pain, it is quite natural for one to think first of functional overlay and tend to attribute the pain to a psychosomatic cause. This is understandable because most patients with angina pain of moderate duration, particularly if they had normal coronary angiography, do indeed manifest nervousness and anxiety about their condition. However, most of these patients have chest wall pain because of organic systems capable of 
inducing angina such as cervical spine or gastrointestinal disorders, before considering a psychosomatic basis as the only diagnosis.

\section{Mechanism of Chest Pain}

Although many reports paid attention to cervical angina, the mechanisms of pain production in cervical angina have been a matter of considerable speculation. Most cases with cervical angina have been attributed to cervical nerve root compression [17,18]. Anatomically, the cervical nerve root emerges from the spinal cord over the top of each vertebra, except for the eighth, which reportedly comes out of the spine under the seventh cervical vertebra. The lower four cervical nerves, together with the first thoracic nerve, form the brachial plexus innervating parts of chest wall. Nachlas [6] first presented a plausible theory: the medial anterior thoracic nerve, originating from the eighth cervical and first thoracic nerve roots, and the lateral anterior thoracic nerve, originating from the sixth and seventh cervical roots, innervate the pectoralis major and minor muscles. These nerves, primarily motor in function, do not carry sensory fibers, but they can possess protopathic sensibility. Nerve constriction in this area might then induce diffuse pain that is referred to the terminal portion of the nerve. Brain et al. [19] and Frykholm [20] speculated that ventral nerve root compression at the cervical foramina can induce several symptoms, including radicular pain. However, the pain is not clearly radicular but is less discrete, which may be referred to a muscle innervated by the cervical myotomes, resulting in precordial pain. Patients with cervical angina are more likely to have a disorder at the C6 or C7 level. In 1985, Brodsky [4] reported the largest series of 438 cases with cervical angina; he was able to make a deep insight into its physiological etiology. He suggested that radicular pain is mediated by compression of the $\mathrm{C} 4-\mathrm{C} 8$ nerve roots, which supply sensory and motor innervations to the anterior chest wall through the medial and lateral pectoral nerves. The most frequently affected levels were not only limited to C6-7 levels (30\%) but also the C5-6 (37\%), C4-5 (27\%), and C3-4 levels (4\%) [4]. A similar conclusion that nerve root compression could also be the origin of precordial pain was verified in the observation of Jacobs [2]. Divisions of the anterior roots of $\mathrm{C}-5$ to $\mathrm{T}-1$ give origin to a number of individual nerves that supply motor, sensory, and autonomic fibers to the upper thorax, shoulder, and arm.
The efficacy of symptom relief after cervical diskectomy and fusion, in return, further proves the theory of cervical nerve root compression in cervical angina.

Secondly, some studies have hypothesized that the cervical angina may be mediated by the cervical sympathetic afferent fibers to the heart and coronary arteries. The cervical sympathetic chain is located posteromedial to the carotid sheath, which runs over the longus muscles. It extends longitudinally from the longus capitis to the longus colli over the muscles and under the prevertebral fascia. In 1959, Cloward [16] reported that an abnormality of the sympathetic nervous system caused precordial discomfort. Other autonomic symptoms, such as nausea and diaphoresis, can occur and are mediated through the sympathetic nervous system, although the exact mechanism remains to be unknown. Tanaka [21] reported that selective nerve block has diminished both chest pain and nerve root symptoms, whereas a sympathetic stellate ganglion block reportedly diminished the chest pain without affecting the root symptoms.

Third, referred pain may be another potential mechanism of pseudo-angina, wherein nerve root compression is determined to be absent but present with cervical disk degeneration, facet joint pathology, or ossification of the posterior longitudinal ligament (OPLL) [22-25]. Referred pain may be mediated by sinuvertebral nerve, which is a branch from the initial part of each spinal nerve passing in a recurrent fashion back through the intervertebral foramen to supply the spinal meninges, the posterior longitudinal ligament, posterolateral periphery of the intervertebral disc, and periosteum of the vertebrae. Last but not the least, lesions of the posterior horn of the spinal cord or irritation of the ascending cardiac spinothalamic tracts may develop into angina pain [26]. A similar explanation would also apply to cervical angina cases attributed to cervical myelopathy [3], spinal cord tumors [27], and spinal cord infarction $[28,29]$. The mechanism underlying chest pain is still controversial. Published literatures regarding the mechanism of chest pain in cervical angina are presented in Table 1 [2-4,6-13,16-31].

\section{Treatment}

Conservative treatment has been determined to be successful in most patients with cervical angina. A simple neck collar fixation or head traction can help relieve pain $[4,6,30]$. Other treatments include physical therapy, 
Table 1. Published literatures regarding mechanism of chest pain in cervical angina

\begin{tabular}{|c|c|}
\hline Reference & Case \\
\hline \multicolumn{2}{|l|}{ Radicular (nerve root compression) } \\
\hline Nachlas [6] (1934) & 3 \\
\hline Hanflig [10] (1936) & 1 \\
\hline Semmes and Murphey [9] (1943) & 4 \\
\hline Michelsen and Mixter [11] (1944) & 1 \\
\hline Davis [12] (1950) & 3 \\
\hline Brain et al. [19] (1952) & 2 \\
\hline Frykholm [20] (1953) & 1 \\
\hline Forrester et al. [31] (1970) & 10 \\
\hline Iwasa [8] (1976) & 3 \\
\hline Brodsky [4] (1985) & 88 \\
\hline Jacobs [2] (1990) & 164 \\
\hline Yeung and Hagen [17] (1993) & 2 \\
\hline Wells [13] (1997) & 1 \\
\hline Guler et al. [30] (2000) & 2 \\
\hline Mork et al. [18] (2004) & 1 \\
\hline Nakajima et al. [3] (2006) & 10 \\
\hline Sussman et al. [7] (2015) & 6 \\
\hline \multicolumn{2}{|c|}{ Sympathetic nervous system (autonomic symptoms) } \\
\hline Cloward [16] (1959) & 1 \\
\hline Tanaka [21] (1976) & 1 \\
\hline Brodsky [4] (1985) & 88 \\
\hline Sussman et al. [7] (2015) & 6 \\
\hline \multicolumn{2}{|c|}{$\begin{array}{l}\text { Referred pain (cervical instability, facet joint pathology, } \\
\text { ossification of the posterior longitudinal ligament) }\end{array}$} \\
\hline Ozgur and Marshall [22] (2003) & 39 \\
\hline Ito et al. [24] (2004) & 1 \\
\hline Sudo and Goto [25] (2012) & 1 \\
\hline Zussman et al. [23] (2012) & 1 \\
\hline \multicolumn{2}{|c|}{$\begin{array}{l}\text { Lesions of the posterior horn of the spinal cord (cervical } \\
\text { myelopathy spinal cord tumor spinal cord infarction) }\end{array}$} \\
\hline LaBan et al. [26] (1979) & 15 \\
\hline Akiyama et al. [27] (1994) & 1 \\
\hline Cheshire [28] (2000) & 1 \\
\hline Nakajima et al. [3] (2006) & 10 \\
\hline Nakae et al. [29] (2013) & 1 \\
\hline Sussman et al. [7] (2015) & 6 \\
\hline
\end{tabular}

Some literatures had multiple mechanisms of cervical angina.

nonsteroidal anti-inflammatory drugs, and muscle relaxants. At least 3 months of conservative treatment are recommended in all but the most severe cases. Treatment response depends on the severity of the underlying pathology. Conservative treatment should continue as long as the patient's condition improves. Some patients even experienced spontaneous resolution of the angina symptoms at rest $[2,7]$.

However, surgical intervention may be recommended if conservative measures fail or in cases where neurologic compromise is evident by spinal cord and/or nerve root compression. Brodsky [4] reported the largest series of 438 cases with cervical angina, wherein 88 (20.1\%) of the patients were surgically treated mostly by anterior approach. The most common level identified was C5-6 (36.6\%), followed by C6-7 (30.2\%) and C4-5 (26.8\%). In the early years of this series, posterior approach with laminectomy and foraminotomy was used exclusively in a small series. An anterior approach was used for the remaining 78 patients. Most cases underwent multiple levels of surgery. After operation, 68 patients (78.2\%) were assessed to be in excellent grade (relief of preoperative chest pain), 12 patients $(13.8 \%)$ in fair grade (occasionally mild chest pain requiring no medications), and four patients (4.6\%) in poor grade (continued same or less severe chest pain, requiring occasional medication). Nakajima et al. [3] also reported a series of 10 patients diagnosed with cervical angina, whose background disease was cervical spondylotic myelopathy (three cases), cervical disc herniation (six cases), and OPLL (one case). The affected levels were C4-5 level in three cases, C5-6 level in four cases, and C6-7 level in three cases. Chest pain in all patients was completely relieved by anterior cervical surgery decompression. Ozgur and Marshall [22] reported that approximately $90 \%$ of patients have experienced long-term relief after anterior cervical discectomy and fusion. Therefore, anterior cervical surgery to correct nerve root or spinal cord compression has proved to be a useful option for pain relief in cervical angina [23].

\section{Prospection}

In our practical experience, some cervical angina patients present with hyperplasia of the Luschka's joint in their degenerative cervical spines. They underwent anterior cervical decompression surgery with complete resection of the Luschka's joint osteophytes [32]. Fortunately, the chest pain symptoms disappeared soon after the surgery, and no relapse occurred during the follow-up. The patients were very satisfied with the surgical outcomes. Therefore, it is 
reasonable to speculate a close association between cervical angina and the Luschka's joint osteophytes.

In previous anatomical studies [33-35], cervical sympathetic trunk (CST) extends longitudinally from the longus capitis to the longus colli over the muscles and under the prevertebral fascia. The longus colli muscles diverge laterally, whereas the sympathetic trunks converge medially at C6. CSTs are situated at $11.6 \pm 1.6 \mathrm{~mm}$ lateral to the medial border of the longus colli muscle [36]. Because the sympathetic trunk has been determined to be situated closer to the medial border of the longus colli muscle at the lower cervical spine region, it may be more vulnerable to irritation [37]. In anterior lower cervical spine procedures, extensive dissection or CST compression by the retractor causes CST injury. Similarly, we hypothesize

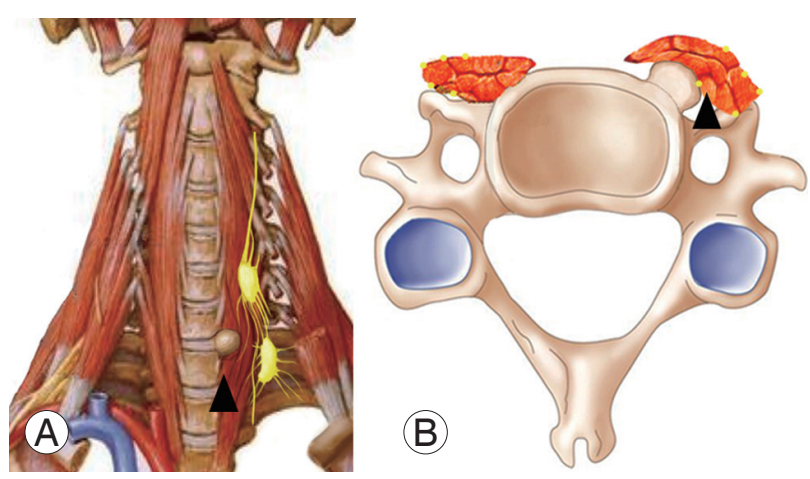

Fig. 1. (A, B) Illustrative diagram of the Luschka's joint and how its osteophytic hypertrophy can affect the adjacent sympathetic nerves, which might result in cervical angina (arrowhead). that the protrusion of Luschka's joint osteophytes jacks up the homolateral longus colli, which might compress or stimulate adjacent sympathetic afferent fibers to the heart and coronary arteries and result in noncardiac chest pain (Fig. 1). In addition, the course of lateral attachment of white rami communicantes [36], which are identified as branches of the sympathetic trunk to the cardiac nerves, is just located at the area of Luschka's joint, which may be another potential mechanism for this cervicogenic chest pain. However, this kind of speculation is based mostly on our clinical case experience. We reported this interesting phenomenon to raise more awareness on cervical angina and its pathogenic factor. Further pathological explanations should be explored in future studies.

\section{Conclusions}

Despite the fact that cervical angina is a rare disease, physicians and spine surgeons should be familiar with it for diagnosis and treatment (Table 2). The possibility of cervical angina should be considered once myocardial ischemia is ruled out in patients with inadequately explained chest pain, especially when neurologic signs and symptoms are also present. Raising more awareness on this unusual radiating pattern for cervical pathology will hopefully lead to early diagnosis and a recognition that this symptom pattern is not caused by dual clinical entities but, instead, unified by the diagnosis of cervical angina. It is essential that more family doctors, internists, and spine surgeons are more aware of this condition. Anterior cervical sur-

Table 2. Manifestations and treatments in cervical angina

\begin{tabular}{lll}
$\begin{array}{l}\text { Location of chest pain } \\
\text { Common }\end{array}$ & Associated symptoms/neurologic signs & \multicolumn{1}{c}{ Treatments } \\
\hline Precordial pain & Arm radicular symptoms (pain or numbness) & NSAIDs or muscle relaxant \\
\hline Left anterior chest pain & Neck pain and tenderness & Cervical collar \\
\hline & Headache & Head traction \\
\hline Lutonomic symptoms & Physical therapy \\
\hline Substernal pain & Surpling's sign & - \\
\hline Retrosternal pain & & \\
\hline Scapular pain & Increased or decreased tendon reflexes & Anterior cervical discectomy (92.7\%, 165 cases) \\
\hline Right chest pain & Muscle atrophy & Posterior approach cervical surgery (7.3\%, 13 cases) \\
\hline
\end{tabular}

Autonomic symptoms include dyspnea, nausea, vertigo, diplopia, and diaphoresis.

NSAIDs, nonsteroidal anti-inflammatory drugs. 
gery with complete decompression of spinal cord and/or nerve root has been identified to effectively resolve cervical angina symptoms. Luschka's joint osteophytes may be one of pathogenic factors in cervical angina, but it needs further pathological study in the future.

\section{Conflict of Interest}

No potential conflict of interest relevant to this article was reported.

\section{Acknowledgments}

This work was supported by National Natural Science Foundation of China (81672203) and Interdisciplinary Program of Shanghai Jiao Tong University (YG2017ZD07).

\section{References}

1. Pope JH, Aufderheide TP, Ruthazer R, et al. Missed diagnoses of acute cardiac ischemia in the emergency department. N Engl J Med 2000;342:1163-70.

2. Jacobs B. Cervical angina. N Y State J Med 1990;90:811.

3. Nakajima H, Uchida K, Kobayashi S, et al. Cervical angina: a seemingly still neglected symptom of cervical spine disorder? Spinal Cord 2006;44:509-13.

4. Brodsky AE. Cervical angina: a correlative study with emphasis on the use of coronary arteriography. Spine (Phila Pa 1976) 1985;10:699-709.

5. Phillips J. The importance of examination of the spine in the presence of intrathoracic or abdominal pain. Proc Int Postgrad MA North Am 1927;3:70.

6. Nachlas IW. Pseudo-angina pectoris originating in the cervical spine. JAMA 1934;103:323-5.

7. Sussman WI, Makovitch SA, Merchant SH, Phadke J. Cervical angina: an overlooked source of noncardiac chest pain. Neurohospitalist 2015;5:22-7.

8. Iwasa M. Clinical analysis of angina pectoris and angina-like pain: with special reference to ECG during attack, "cervical spondylosis" and selective coronary arteriography. Jpn Circ J 1976;40:1191-203.

9. Semmes RE, Murphey F. The syndrome of unilateral rupture of the sixth cervical intervertebral disk: with compression of the seventh cervical nerve root a report of four cases with symptoms simulating coro- nary disease. JAMA 1943;121:1209-14.

10. Hanflig SS. Pain in the shoulder girdle, arm and precordium due to cervical arthritis. JAMA 1936;106:523-6.

11. Michelsen JJ, Mixter WJ. Pain and disability of shoulder and arm due to herniation of the nucleus pulposus of cervical intervertebral disks. New Eng J Med 1944;231:279-87.

12. Davis D. Respiratory manifestations of dorsal spine radiculitis simulating cardiac asthma. Ann Intern Med 1950;32:954-9.

13. Wells P. Cervical angina. Am Fam Physician 1997;55:2262-4.

14. Constant J. The diagnosis of nonanginal chest pain. Keio J Med 1990;39:187-92.

15. Christensen HW, Vach W, Gichangi A, Manniche C, Haghfelt T, Hoilund-Carlsen PF. Cervicothoracic angina identified by case history and palpation findings in patients with stable angina pectoris. J Manipulative Physiol Ther 2005;28:303-11.

16. Cloward RB. Cervical diskography: a contribution to the etiology and mechanism of neck, shoulder and arm pain. Ann Surg 1959;150:1052-64.

17. Yeung MC, Hagen NA. Cervical disc herniation presenting with chest wall pain. Can J Neurol Sci 1993;20:59-61.

18. Mork AA, Haufe SM, Yancey WB. Sometimes (what seems to be) a heart attack is (really) a pain in the neck. J Am Board Fam Pract 2004;17:74-7.

19. Brain WR, Northfield D, Wilkinson M. The neurological manifestations of cervical spondylosis. Brain 1952;75:187-225.

20. Frykholm R. On pain sensations produced by the stimulation of ventral roots in man. Acta Physiol Scand 1953;106:455-69.

21. Tanaka S. Etiological consideration of cervical angina combined with cervical disc herniation. Jpn Orthop J 1976;19:875-7.

22. Ozgur BM, Marshall LF. Atypical presentation of C-7 radiculopathy. J Neurosurg 2003;99(2 Suppl):169-71.

23. Zussman BM, Saldua NS, Harrop JS. Cervical instability presenting as thoracic pain: case report and literature review. J Spinal Cord Med 2012;35:125-7.

24. Ito Y, Tanaka N, Fujimoto Y, Yasunaga Y, Ishida O, Ochi M. Cervical angina caused by atlantoaxial instability. J Spinal Disord Tech 2004;17:462-5.

25. Sudo H, Goto R. Cervical angina because of ossifica- 
tion of the posterior longitudinal ligament. Spine J 2012;12:169.

26. LaBan MM, Meerschaert JR, Taylor RS. Breast pain: a symptom of cervical radiculopathy. Arch Phys Med Rehabil 1979;60:315-7.

27. Akiyama H, Tamura K, Takatsuka K, Kondo M. Spinal cord tumor appearing as unusual pain. Spine (Phila Pa 1976) 1994;19:1410-2.

28. Cheshire WP Jr. Spinal cord infarction mimicking angina pectoris. Mayo Clin Proc 2000;75:1197-9.

29. Nakae Y, Johkura K, Kudo Y, Kuroiwa Y. Spinal cord infarction with cervical angina. J Neurol Sci 2013;324:195-6.

30. Guler N, Bilge M, Eryonucu B, Cirak B. Acute ECG changes and chest pain induced by neck motion in patients with cervical hernia: a case report. Angiology 2000;51:861-5.

31. Forrester JS, Herman MV, Gorlin R. Noncoronary factors in the anginal syndrome. $\mathrm{N}$ Engl J Med 1970;283:786-9.
32. Zhang F, Huang X, Chen XG, et al. Bowstring effect of longus colli secondary to Luschka's joint hyperplasia: a potential factor contributing to cervical angina. Int J Clin Exp Med 2018;11:2264-70.

33. Yin Z, Yin J, Cai J, Sui T, Cao X. Neuroanatomy and clinical analysis of the cervical sympathetic trunk and longus colli. J Biomed Res 2015;29:501-7.

34. Saylam CY, Ozgiray E, Orhan M, Cagli S, Zileli M. Neuroanatomy of cervical sympathetic trunk: a cadaveric study. Clin Anat 2009;22:324-30.

35. Kiray A, Arman C, Naderi S, Guvencer M, Korman E. Surgical anatomy of the cervical sympathetic trunk. Clin Anat 2005;18:179-85.

36. Civelek E, Karasu A, Cansever T, et al. Surgical anatomy of the cervical sympathetic trunk during anterolateral approach to cervical spine. Eur Spine J 2008;17:991-5.

37. Ebraheim NA, Lu J, Yang H, Heck BE, Yeasting RA. Vulnerability of the sympathetic trunk during the anterior approach to the lower cervical spine. Spine (Phila Pa 1976) 2000;25:1603-6. 